\title{
Major and Minor Electrocardiographic Abnormalities and their Association with Underlying Cardiovascular Disease and Risk Factors in Hispanics/Latinos (From the Hispanic Community Health Study/Study of Latinos [HCHS/SOL])
}

\author{
Pablo Denes, MD, MPH ${ }^{a}$, Daniel B. Garside, BSa, Donald Lloyd-Jones, MDa ${ }^{a}$, Natalia \\ Gouskova, MS ${ }^{e}$, Elsayed Soliman, MD, MSc ${ }^{\mathrm{c}, \mathrm{d}}$, Robert Ostfeld, MD, MSc ${ }^{g}$, Zhu-Ming Zhang, \\ MD, MPH ${ }^{c, d}$, Alvaro Camacho, MD, MPH ${ }^{f}$, Ronald Prineas, MBBS, PhD ${ }^{c, d}$, Leopoldo Raij, \\ $\mathbf{M D}^{\mathrm{h}}$, and Martha L. Daviglus, MD, $\mathrm{PhD}^{\mathrm{b}}$ \\ aDepartments of Medicine and Preventive Medicine, Feinberg School of Medicine, Northwestern \\ University, Chicago, IL \\ bepartment of Medicine, College of Medicine, University of Illinois at Chicago \\ 'Epidemiological Cardiology Research Center (EPICARE) and Departments of Epidemiology and \\ Prevention, and Internal Medicine (Cardiology Section), Wake Forest School of Medicine, \\ Winston Salem, NC \\ dDivision of Public Health Sciences, Wake Forest University School of Medicine, Winston Salem, \\ NC \\ ${ }^{e}$ Collaborative Studies Coordinating Center, University of North Carolina at Chapel Hill, NC \\ fUniversity of California, San Diego affiliated investigator, Imperial, CA \\ ${ }^{g}$ Albert Einstein College of Medicine, Montefiore Medical Center, Bronx, NY \\ hUniversity of Miami, Miller School of Medicine/VAMC, Miami, FL
}

\begin{abstract}
The association of ECG abnormalities with cardiovascular disease and risk factors has been extensively studied in Whites and African Americans. Comparable data have not been reported in Hispanics/Latinos. The Hispanic Community Health Study/Study of Latinos (HCHS/SOL) is a multicenter community based prospective cohort study of men and women of diverse backgrounds ages 18 to 74 years who self-identified as Hispanic/Latinos. Participants $(\mathrm{N}=16,415)$, enrolled between March 2008 and June 2011. We describe the prevalence of minor and major ECG abnormalities and examine their cross-sectional associations with cardiovascular disease and risk factors. The Minnesota code criteria were used to define minor and major abnormalities of the ECG. Prior cardiovascular disease and risk factors were based on data obtained at baseline examination. Significant differences in prevalent ECG findings were found between men and
\end{abstract}

(C) 2013 Excerpta Medica, Inc. All rights reserved.

Corresponding Author: Pablo Denes, MD, MPH, 676 N. St. Clair, Suite 600, Chicago, Il 60611, P| 312.926.2153, F| 312.695.0063, pdenes@northwestern.edu.

None of the authors had any financial or other conflicts of interest.

Publisher's Disclaimer: This is a PDF file of an unedited manuscript that has been accepted for publication. As a service to our customers we are providing this early version of the manuscript. The manuscript will undergo copyediting, typesetting, and review of the resulting proof before it is published in its final citable form. Please note that during the production process errors may be discovered which could affect the content, and all legal disclaimers that apply to the journal pertain. 
women. Major ECG abnormalities were present in $9.2 \%$ ( 95\% confidence interval [CI], 8.3-10.1) of men and 6.6\% (95\% CI, 5.8-7.3) of women ( $\mathrm{P}<.0001)$. The odds of having major ECG abnormalities significantly increased with age, presence of 3 or more cardiovascular risk factors and prevalent cardiovascular disease, in both men and women. Significant differences in major ECG abnormalities were found among the varying groups; Puerto Ricans and Dominicans had more major abnormalities compared to Mexican men and women. In conclusion, a large cohort of Hispanic/Latino men and women, prevalence of major abnormalities were low yet strong associations of major ECG abnormalities with cardiovascular disease and risk factors were observed in both men and women.

\section{Keywords}

Electrocardiogram; Hispanic Community Health Study/Study of Latinos (SOL); cardiovascular risk factors

\section{Introduction}

The electrocardiogram (ECG) has been used as an inexpensive and widely available screening tool for the detection of the presence of cardiovascular disease $(1,2)$. The association of ECG abnormalities and underlying cardiovascular disease and the prognostic significance of the ECG have been extensively studied in Whites, and African Americans, and also reported in American Indians and Americans of Japanese descent but not in Hispanics (1-18). There is only limited information on ECG findings in the Hispanic population (19-23). Most studies compared specific ECG findings such as QRS voltage, ST height, and QT prolongation in racially diverse populations including Hispanics (20-23).

The HCHS/SOL includes both men and women with a wide range of age, multiple countries of origin, and individuals with and without a history of heart disease and cardiovascular risk factors (24). The present study compares prevalent ECG findings between Hispanic/Latino men and women and evaluates the association of ECG findings with age and gender in the presence or absence of underlying heart disease and cardiovascular risk factors. Specifically, it examines the prevalence of minor and major baseline ECG abnormalities and their association with underlying cardiovascular disease and risk factors in a diverse group of Hispanic/Latino men and women.

\section{Methods}

The HCHS/SOL is a population-based cohort study designed to examine risk and protective factors for chronic diseases and to quantify morbidity and mortality prospectively. Details of the sampling methods and design have been published. $(24,25,26)$. Briefly, between March 2008 and June 2011, 16415 self-identified Hispanic/Latino persons of diverse background (Cubans, Dominicans, Mexicans, Puerto Ricans, Central Americans, and South Americans) aged 18 to 74 years were examined. Participants were recruited from randomly selected households in 4 US communities (Bronx, New York; Chicago, Illinois; Miami, Florida; San Diego, California). Households were selected using a stratified 2-stage area probability sample design. $(25,26)$. Census block groups were randomly selected in the defined community areas of each field center, and households were randomly selected in each sampled block group. Households were screened for eligibility, and Hispanic/Latino persons aged 18 to 74 years were selected in each household agreeing to participate. Oversampling occurred at each stage, with block groups in areas of Hispanic/ Latino concentration, households associated with a Hispanic/Latino surname, and persons aged 45 to 74 years selected at higher rates than their counterparts. Sampling weights were generated to reflect the probabilities of selection at each stage. The study was approved by the institutional 
review board at each participating institution; written informed consent was obtained from all participants $(24,25,26)$.

The study design and study protocol and implementation have been previously published in detail $(24,25,26)$. The baseline examination included medical history, medication use, family history, tobacco use, anthropometry, blood pressure, phlebotomy for laboratory studies and an ECG. Major CVD risk factors were defined based on current national guidelines.

Hypercholesterolemia and dyslipidemia were defined as total cholesterol $240 \mathrm{mg} / \mathrm{dL}$ or greater, LDL cholesterol $160 \mathrm{mg} / \mathrm{dL}$ or greater, or HDL cholesterol less than $40 \mathrm{mg} / \mathrm{dL}$ (for persons with and without diabetes) or receiving cholesterol-lowering medication (24). Hypertension was a systolic blood pressure $140 \mathrm{~mm} \mathrm{Hg}$ or greater, diastolic blood pressure $90 \mathrm{~mm} \mathrm{Hg}$ or greater or receiving antihypertensive medication (24). Diabetes mellitus was a fasting plasma glucose $126 \mathrm{mg} / \mathrm{dL}$ or greater, 2-hour post-load plasma glucose $200 \mathrm{mg} / \mathrm{dL}$ or greater, an $\mathrm{HbA} 1 \mathrm{c} 6.5 \%$ or greater, or use of antihyperglycemic medications (24). Blood pressure and heart rate were measured by standard epidemiology procedures ( 5 minutes rest, 3 measures), using an automated blood pressure device [Omron model HEM-907 XL(Omron Healthcare Inc, Bannockburn, IL)] in a seated position. Smoking status was categorized as current smoker, past smoker, and never smoked. A positive family history of CVD was defined as answering yes to the question of having a first degree relative who had a heart attack at age $<55$ years old. The presence of prior CVD was ascertained by answering yes to the questions of having had prior heart attack, coronary revascularization (CABG or PTCA/stent), rheumatic heart disease, heart failure or stroke/TIA. ECGs were obtained after an overnight fast and at least 2 hours after glucose load administration.

Resting standard, 10 second, simultaneous 12-lead ECG was digitally acquired using a GE MAC 1200 electrocardiograph (GE, Milwaukee, WI) at $10 \mathrm{~mm} / \mathrm{mV}$ calibration and speed of $25 \mathrm{~mm} / \mathrm{s}$. ECG reading was performed centrally at the Epidemiological Cardiology Research Center (EPICARE), Wake Forest School of Medicine, Winston Salem, NC. All ECGs were initially inspected visually for technical errors and inadequate quality before being automatically processed using GE 12-SL Marquette Version 2001(GE, Milwaukee, WI). ECG abnormalities were classified and coded using the Minnesota ECG Classification (27). In addition to the individual ECG abnormalities, ECG tracings were classified as having a major or minor abnormality. Participants with only minor ECG abnormalities were classified as having "any minor abnormalities," and participants with major ECG abnormalities with or without coexisting minor ECG abnormalities were classified as having "any major ECG abnormalities." Major ECG abnormalities included: Major ventricular conduction defect; definite myocardial infarction (defined as the presence of major Q wave abnormalities); possible myocardial infarction (defined as the presence of minor Q-QS wave plus major ST-T abnormalities); major isolated ST-T abnormalities; left ventricular hypertrophy plus major ST-T abnormalities; major atrio-ventricular conduction abnormalities; major QT prolongation (QTI $\geq 116 \%$ or JTI if QRS $\geq 120 \mathrm{~ms}$ ), pacemaker, and other major arrhythmias. Minor ECG abnormalities included: Minor isolated Q-QS waves; minor isolated ST-T abnormalities; high R waves; ST segment elevation; incomplete right bundle branch block; minor QT prolongation (QTI $\geq 112 \%$ or JTI if QRS $\geq 120 \mathrm{~ms}$ ); short PR interval; left axis deviation; right axis deviation; frequent ventricular premature beats; and other minor abnormalities.

In addition to the Minnesota code defined ECG abnormalities, the automatically calculated global measurements of QT, PR, and QRS were also obtained. To calculate QTc interval from the raw QT and heart rate, recommendation of using linear models for adjustment for QTc from the American Heart Association (AHA), American College of Cardiology (ACC) and Heart Rhythm Society (HRS) for the Standardization and Interpretation of the 
Electrocardiogram were followed(28). Therefore, the Framingham linear regression formula $[\mathrm{QTc}=\mathrm{QT}+0.154(1-\{60 /$ heart rate $\})]$ was used (29). QTc values of $460 \mathrm{~ms}$ or longer in women and $450 \mathrm{~ms}$ or longer in men were considered abnormal (i.e. prolonged QTc) (27).

The HCHS/SOL cohort was recruited with use of a stratified two-stage area probability sampling design in which participant's households were sampled from augmented residential mailing lists from pre-selected census block groups within each of the four regional field centers. The target population was the non-institutionalized Hispanic/Latino population ages 18-74 residing in the defined community areas. Trimmed, normalized sampling weights adjusted for non-response for enumerated but non-enrolled household members were derived and later calibrated to the 2010 US Census. Complete details of the sampling design have been reported in a technical report prepared by the study coordinating center. To account for the complex sampling design, all reported means and proportions are weighted. Model based means, proportions, odds ratios and p-values were obtained by fitting linear and logistic regression models for complex survey data. Standard errors were computed by using Taylor linearization method. All analysis were performed using SAS 9.3 survey specific procedures (SAS Institute, Cary, NC). Participants with missing ECG readings $(\mathrm{N}=203)$ and missing data on CVD risk factors $(\mathrm{N}=284)$; includes (9 participants > 74 years old, and 152, 49, 18, 71, 144 and 13 missing one or more of serum cholesterol, BMI, blood pressure, smoking, family history of CVD or diabetes status, respectively) and CVD status variables $(\mathrm{N}=116)$ were excluded from all analyses, leaving 15,812 participants in the analysis sample. To preserve the study design and ensure that the standard errors are computed correctly, the exclusions were made by using the DOMAIN statement in SAS survey procedures. Weighted prevalence percents have been age standardized to the year 2000 Census to make them more comparable to NHANES data (30).

\section{Results}

Baseline characteristics of the study group are shown in Table 1. At baseline examination, men had higher prevalence of history of hypercholesterolemia, being current smokers, having history of heart attack and coronary revascularization; they had higher systolic and diastolic blood pressure. Women were older, more obese, and had faster heart rates.

The prevalent age adjusted major and minor ECG abnormalities comparing men and women are shown in Table 2. Major ECG abnormalities were more frequent in men. The three more common major ECG abnormalities in men were major Q waves (MC 1.1, 1.2), ventricular conduction defects (MC 7.1, 7.2, 7.4, 7.8) and major isolated ST-T abnormalities (MC $4.1 \mathrm{o}$ 4.2 or 5.1 or 5.2). In women these ECG abnormalities had also the highest prevalence but compared to men the prevalence of major $\mathrm{Q}$ waves (MC 1.1, 1.2), and ventricular conduction defects (MC 7.1, 7.2, 7.4, 7.8) were significantly lower and major isolated ST-T abnormalities (MC 4.1 o 4.2 or 5.1 or 5.2) were higher. There were significant differences in the prevalence of certain minor ECG abnormalities. Men had a higher prevalence of minor isolated Q waves (MC 1.3), tall R waves (MC 3.1, 3.3, 3.4), ST elevation (MC 9.2), incomplete right bundle branch block (MC 7.3), left axis deviation (MC 2.1), frequent VPB $(8.1 .2,8.1 .3)$ and sinus bradycardia (MC 8.8). Women had a higher prevalence of minor isolated ST-T abnormalities (MC 4.3, 4.4, 5.3, 5.4), low QRS voltage (MC 9.1) and minor QT prolongation index.

The comparison of the prevalent ECG findings and major and minor ECG abnormalities by CVD risk status or disease in men and women is shown in Tables 3 and 4. There was a significant trend, in both men and women, for increasing heart rate, QRS and QTc duration and QT prolongation index as the number of CVD risk factors increased or in the presence of prevalent CVD, compared to those with no CVD risk factors. Examining major ECG 
abnormalities in men there was a significant trend for increasing prevalence of major $\mathrm{Q}$ waves (MC 1.1, 1.2), major isolated ST-T abnormalities (MC 4.1 o 4.2 or 5.1 or 5.2), left ventricular hypertrophy plus major ST-T abnormality $\{\mathrm{MC} 3.1+(4.1$ or 4.2 or 5.1 or 5.2$)\}$ and ventricular conduction defects (MC 7.1, 7.2, 7.4, 7.8) with the number of CVD risk factors and prevalent CVD. The prevalence of any major ECG abnormality was $6.22 \%$ in men without CVD risk factors or disease and $28.44 \%$ in those with prevalent CVD. In women the prevalence of any major ECG abnormality was $5.40 \%$ in those without CVD risk factors or disease and $16.71 \%$ in those with prevalent CVD. In women, significant trends were observed for the presence of major Q waves (MC 1.1, 1.2), major isolated ST-T abnormalities (MC 4.1 o 4.2 or 5.1 or 5.2), left ventricular hypertrophy plus major ST-T abnormality $\{$ MC $3.1+(4.1$ or 4.2 or 5.1 or 5.2$)\}$ and major QT prolongation index (QTI $\geq$ 116) with the number of CVD risk factors and prevalent CVD. Examining minor ECG abnormalities in men there was a significant trend for higher prevalence of minor isolated ST-T abnormalities (MC 4.3, 4.4, 5.3, 5.4) with higher risk factor burden. An inverse trend for ST elevation (MC 9.2) and sinus bradycardia was present with greater risk factor burden. ST elevation (MC 9.2) was observed in $15.24 \%$ of men without CVD risk factors or disease; these were most commonly seen in the inferior leads. In women significant trends were observed for the presence of minor isolated Q waves (MC 1.3), minor isolated ST-T abnormalities (MC 4.3, 4.4, 5.3, 5.4), and tall R waves (MC 3.1, 3.3, 3.4)across the risk factor burden groups. ST elevation in women showed no reverse trend and the prevalence was low $(0.78 \%)$ in those without CVD risk factors or disease.

Cross-sectional associations of major ECG abnormalities with CVD risk factors, prevalent CVD, and ethnic background are shown in figure 1. The odds of having major ECG abnormalities was significantly increased in men with age (1 SD delta), history of hypertension, diabetes, current smoker status, heart rate(1 SD delta), systolic and diastolic blood pressure(1 SD delta), 3 or three or more risk factors or prevalent cardiovascular disease. Similar significant associations were found in women except for current smoking status, diastolic blood pressure and three or more CVD risk factors. The odds ratios of having major ECG abnormalities increased in all age groups (years, 35-54, 55-64 and 65 or greater) of both men and women compared to the reference group (years 18-34), even when adjusted for CAD risk factors. The adjusted odds ratio for men age 65 or more for having major ECG abnormalities was 5.6 compared to the reference group and it was 3.5 for women.

The analysis of the effect of age on major ECG abnormalities is shown in figure 2 . The population weighted prevalence $(\%)$ of major ECG abnormalities was higher at older ages in both men and women. The prevalence of major ECG abnormalities increased from $5.7 \%$ in the second decade (18-29 years) to $32.4 \%$ in the seventh decade (70-74 years) in men and $4.7 \%$ to $14.9 \%$ for the corresponding age groups for women. Interestingly, the first significant increase occurred in the fifth decade when the prevalence of major ECG abnormalities doubled.

The HCHS/SOL included participants from Mexican, Cuban, Puerto Rican, Dominican, Central American and South American background. In order to examine if significant differences existed in the odds of having major ECG abnormalities among these groups we designated the Mexican group as reference because they had the largest number of participant in the study. Significant differences in the odds of having major ECG abnormalities were found by ethnic background. The odds of having major ECG abnormalities were significantly higher in Dominicans and Puerto Ricans men and women compared to Mexicans (Figure 1). 


\section{Discussion}

The existing data on ECG findings are derived from largely white population $(1,3-5,7,8$, $10,11,14)$. However, a number of studies have focused on groups with different racial backgrounds. The Strong Heart study examined ECG abnormalities among American Indians (17). The Honolulu Heart Program examined the predictive value of ECG in men of Japanese descent (18). The Evans County and Charleston Heart studies showed that AfricanAmericans have a higher prevalence of ECG abnormalities and less coronary heart disease than White men (6,9). Differences in ECG abnormalities were found in the biracial population of the ARIC, CARDIA and REGARDS studies $(12,13,15,16)$. African American men and women have higher prevalence of ECG abnormalities than Whites $(6,9,12,15,16)$. Other studies reported differences in specific ECG measures such as, QT and QT subintervals, QRS amplitudes, left ventricular hypertrophy and in ST heights in ethnically diverse population (20-23). The largest and most comprehensive study on the value of the ECG in Hispanics was reported from the Palo Alto Veterans Affair (PAVAS) Health Care System (19). The study included 2,625 Hispanic and 41,546 non-Hispanic patients, with $>90 \%$ of them being men. There were fewer CVD deaths in the Hispanic group compared to the non-Hispanics. There were also significant differences in ECG abnormalities between the two groups with the Hispanic showing fewer ECG abnormalities. The study did not report on the major and minor ECG abnormalities but the more frequent abnormalities included pathologic Q waves (10.6\%) and left axis deviation (9.3\%). The analysis was not adjusted for age, or the presence of underlying heart disease and risk factors.

There has been no large community based prospective cohort study examining the prevalence of ECG abnormalities in Hispanic/Latinos. This report on a community based prospective cohort study of large number of Hispanic/Latino men and women provides prevalence estimates of minor and major baseline ECG abnormalities and their associations with underlying cardiovascular disease and risk factors. It also evaluates the effect of age and gender on ECG characteristics. Findings are presented separately for men and women. Data are also weighted to reflect the non-institutional Hispanic/Latino adults residing in the defined community areas of recruitment in each of the four field centers as well as to facilitate subsequent comparison between ethnic groups.

Significant differences in ECG findings between Hispanic/Latino men and women were found. The prevalence of any major ECG abnormality was 6.22\% in men without CVD risk factors or disease and $28.44 \%$ in those with prevalent CVD. In women the prevalence of any major ECG abnormality was $5.40 \%$ in those without CVD risk factors or disease and $16.71 \%$ in those with prevalent CVD. Our results confirm the findings of previous studies not including Hispanic/Latino participants showing a higher prevalence of major ECG abnormalities in men compared to women (1). The more common major abnormalities in men were major Q waves in $2.76 \%$, and major isolated ST-T abnormalities in $3.04 \%$, while in women these were $1.36 \%$ and $3.62 \%$, respectively. The more common minor abnormalities in men were ST segment elevation in $10.18 \%$ and, minor isolated Q/QS waves in $7.71 \%$, while in women these were $1.41 \%$ and $5.75 \%$, respectively. We confirmed previous observations on the association of ST segment elevation with male gender and younger age (1).

The direct association between age and prevalence of major ECG abnormalities was also confirmed by our study (1). The odds ratio of having major ECG abnormalities significantly increased with age, presence of 3 or more cardiovascular risk factors and prevalent cardiovascular disease, in both men and women. The population weighted prevalence of major ECG abnormalities increased from $5.7 \%$ in the second decade (18-29 years) to $32.4 \%$ 
in the seventh decade (70-74 years) in men and $4.7 \%$ to $14.9 \%$ for the corresponding age groups for women.

An interesting finding of our study is the observation that major ECG abnormalities are significantly more likely to be found in both men and women of Puerto Rican and Dominican background compared to Mexicans. This is consistent with the findings of the previous publication on CVD risk factors in Hispanic/Latino individuals, showing that participants with Puerto Rican background have higher prevalence of adverse CVD risk profiles (24). We hypothesize that the higher prevalence of major ECG abnormalities in Dominicans is related to a higher prevalence of participants of African descent. It has been shown that African -Americans have a higher prevalence of ECG abnormalities than nonHispanic Whites $(6,9,12,15,16)$. Further studies are needed to confirm these findings and understand the etiology and mechanism underlying them.

A methodological limitation of the study is that the presence of underlying CVD and some of the risk factors are self-reported and not based on review of medical records. A significant shortcoming of the present report is the absence of follow-up data at the present time to evaluate the prognostic significance of the ECG findings. The major strength includes large cohort study, diverse population of Hispanic/Latinos, uniform measurements, interpretation and reporting of the ECG data by using the Minnesota code classification and computerized ECG from a central reading center (EPICARE).

\section{Acknowledgments}

The authors thank the staff and participants of HCHS/SOL for their important contributions. A complete list of staff and investigators has been provided by Sorlie P., et al. in Ann Epidemiol. 2010 Aug; 20(8):629-41 and is also available on the study website http://www.cscc.unc.edu/hchs/. Ms. Gouskova and Mr. Garside had full access to the study data and take responsibility for the integrity of the data and accuracy of analyses. All authors have reviewed and approved the final manuscript.

Funding

The Hispanic Community Health Study/Study of Latinos was carried out as a collaborative study supported by contracts from the National Heart, Lung, and Blood Institute (NHLBI) to the University of North Carolina (N01HC65233), University of Miami (N01-HC65234), Albert Einstein College of Medicine (N01-HC65235), Northwestern University (N01-HC65236), and San Diego State University (N01-HC65237). The following Institutes/Centers/Offices contribute to the HCHS/SOL through a transfer of funds to the NHLBI: National Center on Minority Health and Health Disparities, the National Institute of Deafness and Other Communications Disorders, the National Institute of Dental and Craniofacial Research, the National Institute of Diabetes and Digestive and Kidney Diseases, the National Institute of Neurological Disorders and Stroke, and the Office of Dietary Supplements.

\section{References}

1. Ashley EA, Raxwal VK, Froelicher VF. The prevalence and prognostic significance of electrocardiographic abnormalities. Curr Probl Cardiol. 2000; 25:1-72. [PubMed: 10705558]

2. Chou R, Arora B, Tracy D, Fu R, Walker M, Humphrey L. Screening Asymptomatic Adults with Resting or Exercise Electrocardiography: A Review of the Evidence for the U.S. Preventive Services Task Force. Ann Intern Med. 2011; 155:375-385. [PubMed: 21930855]

3. The Pooling Project Research Group. Relationship of blood pressure, serum cholesterol, smoking habit, relative weight and ECG abnormalities to incidence of major coronary events: final report of the Pooling Project. J Chronic Dis. 1978; 31:201-306. [PubMed: 681498]

4. Kannel WB, Anderson K, McGee DL, Degatano LS, Stampfer MJ. Nonspecific electrocardiographic abnormality as a predictor of coronary heart disease: the Framingham Study. Am Heart J. 1987; 113:370-376. [PubMed: 3812192]

5. Liao YL, Liu KA, Dyer A, Schoenberger J, Shekelle R, Colette P, Stamler J. Major and minor electrocardiographic abnormalities and risk of death from coronary heart disease, cardiovascular 
diseases and all causes in men and women. J Am Coll Cardiol. 1988; 12:1494-1508. [PubMed: 3192848]

6. Strogatz DS, Tyroler HA, Watkins LO, Hames CG. Electrocardiographic abnormalities and mortality among middle-aged black men and white men of Evans County, Georgia. J Chronic Dis. 1987; 40:149-155. [PubMed: 3818868]

7. Greenland P, Xie X, Liu K, Colangelo L, Liao Y, Daviglus ML, Agulnek AN, Stamler J. Impact of minor electrocardiographic ST-segment and/or T-wave abnormalities on cardiovascular mortality during long-term follow-up. Am J Cardiol. 2003; 91:1068-1074. [PubMed: 12714148]

8. Daviglus ML, Liao Y, Greenland P, Dyer AR, Liu K, Xie X, Huang CF, Prineas RJ, Stamler J. Association of nonspecific minor ST-T abnormalities with cardiovascular mortality: the Chicago Western Electric Study. JAMA. 1999; 281:530-536. [PubMed: 10022109]

9. Sutherland SE, Gazes PC, Keil JE, Gilbert GE, Knapp RG. Electrocardiographic abnormalities and 30-year mortality among white and black men of the Charleston heart study. Circulation. 1993; 88:2685-2692. [PubMed: 8252679]

10. De Bacquer D, De Backer G, Kornitzer M, Blackburn H. Prognostic value of ECG findings for total, cardiovascular disease, and coronary heart disease death in men and women. Heart. 1998; 80:570-577. [PubMed: 10065025]

11. Prineas RJ, Grandits G, Rautaharju PM, Cohen JD, Zhang ZM, Crow RS. MRFIT Research Group. Long-term prognostic significance of isolated minor electrocardiographic T-wave abnormalities in middle-aged men free of clinical cardiovascular disease (the Multiple Risk Factor Intervention Trial [MRFIT]). Am J Cardiol. 2002; 90:1391-1395. [PubMed: 12480053]

12. Vitelli LL, Crow RS, Shahar E, Hutchinson RG, Rautaharju PM, Folsom AR. Atherosclerosis Risk In Communities (ARIC) Study Investigators. Electrocardiographic findings in a healthy biracial population. Am J Cardiol. 1998; 81:453-459. [PubMed: 9485136]

13. Machado DB, Crow RS, Boland LL, Hannan PJ, Taylor HA Jr, Folsom AR. Electrocardiographic findings and incident coronary heart disease among participants in the Atherosclerosis Risk in Communities (ARIC) study. Am J Cardiol. 2006; 97:1176-1181. [PubMed: 16616022]

14. Denes P, Larson JC, Lloyd-Jones DM, Prineas RJ, Greenland P. Major and minor ECG abnormalities in asymptomatic women and risk of cardiovascular events. JAMA. 2007; 297:978985. [PubMed: 17341712]

15. Walsh JA, Prineas R, Daviglus ML, Ning H, Liu K, Lewis CE, Sidney S, Schreiner PJ, Irribarren C, Lloyd-Jones DM. Prevalence of electrocardiographic abnormalities in a middle-aged, biracial population: Coronary Artery Risk Development in Young Adults (CARDIA) study. J Electrocardiol. 2010; 43:385.e1-385.e9. [PubMed: 20374967]

16. Prineas RJ, Le A, Soliman EZ, Zhang Z, Howard VJ, Ostchega Y, Howard G. Reasons for Geographic and Racial Differences In Stroke (REGARDS) Investigators: US National Prevalence of Electrocardiographic Abnormalities in Black and White Middle Aged (45-64 Years) and Older $\geq 65$ Years) Adults (from the Reasons For Geographic and Racial Differences In Stroke Study). Amer J Cardiol. 2012; 109(8):1223-1228. [PubMed: 22245412]

17. Oopik AJ, Dorogy M, Devereux RB, Yeh JL, Okin PM, Lee ET, Cowan L, Fabsitz RR, Howard BV, Welty TK. Major Electrocardiographic Abnormalities Among American Indians Aged 45-74 Years (The Strong Heart Study). Amer J Cardiol. 1996; 78:1400-1405. [PubMed: 8970414]

18. Knutsen R, Knutsen SF, Curb JD, Reed DM, Kautz JA, Yano K. The predictive value of resting electrocardiograms for 12-year incidence of coronary heart disease in the Honolulu Heart Program. J Clin Epidemiol. 1988; 41:293-302. [PubMed: 3339383]

19. Perez MV, Yaw TS, Myers J, Froelicher VF. Prognostic value of the computerized ECG in Hispanics. Clin Cardiol. 2007; 30:189-194. [PubMed: 17443659]

20. Rautaharaju PM, Zhou SH, Calhoun HP. Ethnic differences in ECG amplitudes in North American white, black, men and women: Effect of obesity and age. J of Electrocardiol. 1994; 27:20-31. [PubMed: 7884361]

21. Rautaharaju PM, Prineas RJ, Kadish A, Larson JC, Hsia J, Lund B. Normal standards for QT and QT subintervals derived from a large ethnically diverse population of women aged 50 to 79 years (the Women's Health Initiative, WHI). Am J Cardiol. 2006; 97:730-737. [PubMed: 16490447] 
22. Havranek EP, Froshaug DB, Emserman CDB, Hanratty R, Krants M, Masoudi F, Dickinson LM, Steiner J. Left ventricular hypertrophy and cardiovascular mortality by race and ethnicity. Am J Medicine. 2008; 121:870-875.

23. Reddy VK, Gapstur SM, Prineas RJ, Colangelo LA, Ouyang P, Kadish A. Ethnic differences in ST height in the Multiethnic Study of Atherosclerosis. Ann Noninvasive Electrocardiol. 2008; 13:341-351. [PubMed: 18973491]

24. Daviglus ML, Talavera GA, Aviles-Santa ML, Allison M, Cai J, Criqui M, Gellman M, Giachello A, Gouskova N, Kaplan R, LaVange L, Penedo F, Perreira K, Pirzada A, Schneiderman N, Wassertheil-Smoller S, Sorlie P, Stamler J. Prevalence of Major CardiovascularRisk Factors and Cardiovascular Diseases Among Hispanic/Latino Individuals of Diverse Backgrounds in the United States. JAMA. 2012; 308:1775-1804. [PubMed: 23117778]

25. LaVange LM, Kalsbeek WD, Sorlie PD, Aviles-Santa L, Kaplan R, Barnhart J, Liu K, Giachello A, Lee D, Ryan J, Criqui M, Elder J. Sample Design and Cohort Selection in the Hispanic Community Health Study/Study of Latinos. Ann Epidemiol. 2010; 20:642-649. [PubMed: 20609344]

26. Sorlie PD, Avilés-Santa LM, Wassertheil-Smoller S, Kaplan R, Daviglus M, Giachello A, Schneiderman N, Raij L, Talavera G, Allison M, Lavange L, Chambless L, Heiss G. Design and Implementation of the Hispanic Community Health Study/Study of Latinos. Ann Epidemiol. 2010; 20:629-641. [PubMed: 20609343]

27. Prineas, RJ.; Crow, RS.; Zhang, ZM. The Minnesota Code Manual of Electrocardiographic Findings (Including Measurement and Comparison with the Novacode: Standards and Procedures for Measurement in Epidemiologic and Clinical Trials. 2. London: Springer; 2010.

28. Rautaharju PM, Surawicz B, Gettes LS. AHA/ACCF/HRS recommendations for the standardization and interpretation of the electrocardiogram: Part IV: the ST segment, T and U waves, and the QT interval: A scientific statement from the American Heart Association Electrocardiography and Arrhythmias Committee, Council on Clinical Cardiology; the American College of Cardiology Foundation; and the Heart Rhythm Society. Endorsed by the International Society for Computerized Electrocardiology. J Am Coll Cardiol. 2009; 53:982-91. [PubMed: 19281931]

29. Sagie A, Larson MG, Goldberg RJ, Bengtson JR, Levy D. An improved method for adjusting the QT interval for heart rate (the Framingham Heart Study). Am J Cardiol. 1992; 79:797-801. [PubMed: 1519533]

30. Klein RJ, Schoenborn CA. Age adjustment using the 2000 projected U.S. population. Healthy People 2010 Stat Notes. 2001; 20:1-10. [PubMed: 11676466] 

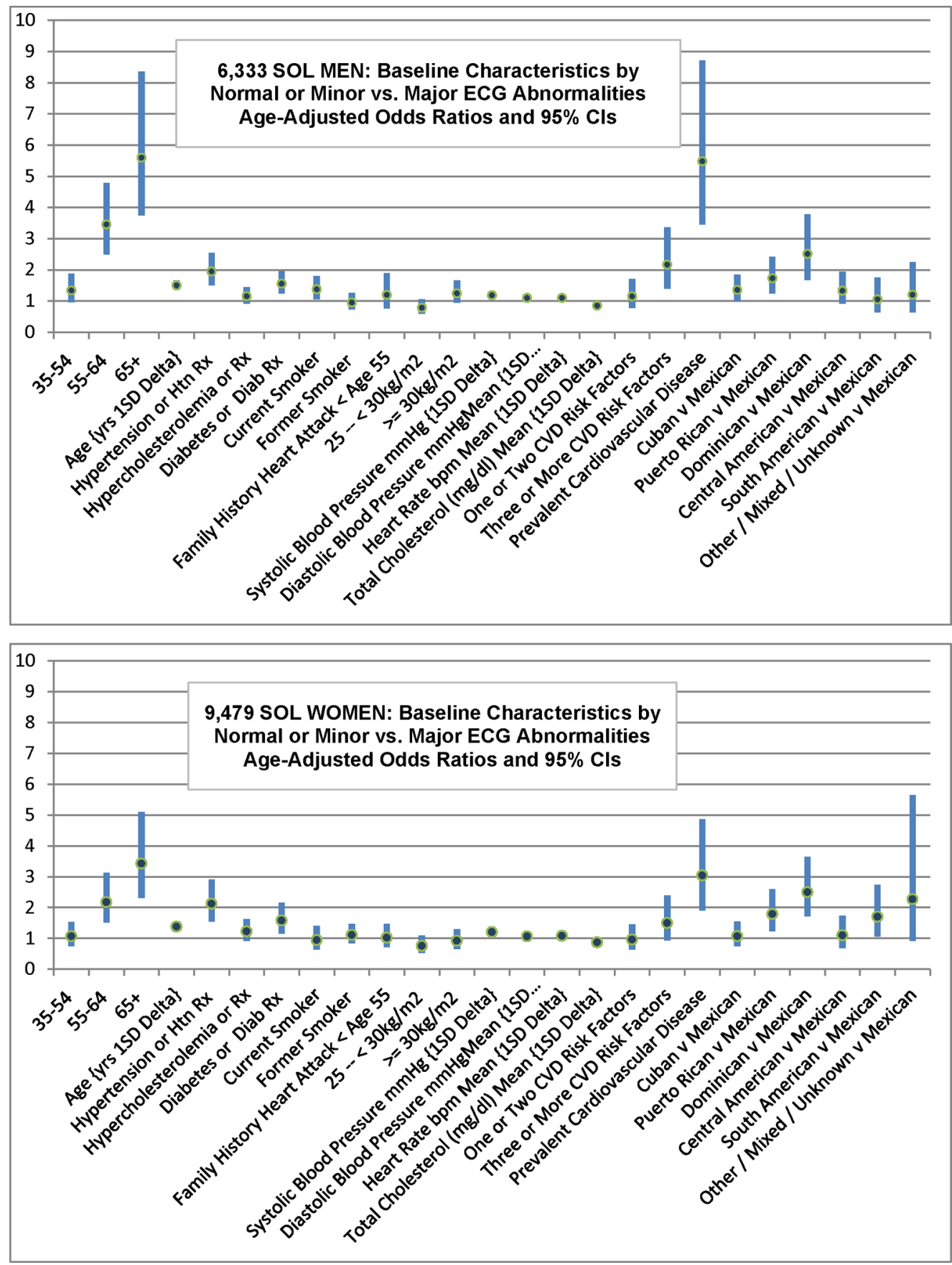

Figure 1.

Baseline characteristic by normal or minor vs. major ECG abnormalities.

Figure 1a. 6,333 HCHS/SOL male participants. Figure 1b. 9,479 HCHS/SOL female participants. Age-adjusted odds ratios and $95 \%$ confidence intervals. Ethnic background odd ratios are further adjusted for hypertension (or medication), hyperlipidemia (or medication), obesity, diabetes (or medication) \& current smoking. CVD $=$ Cardiovascular Disease; Diab= Diabetes; Htn = hypertension; Rx = medication. 


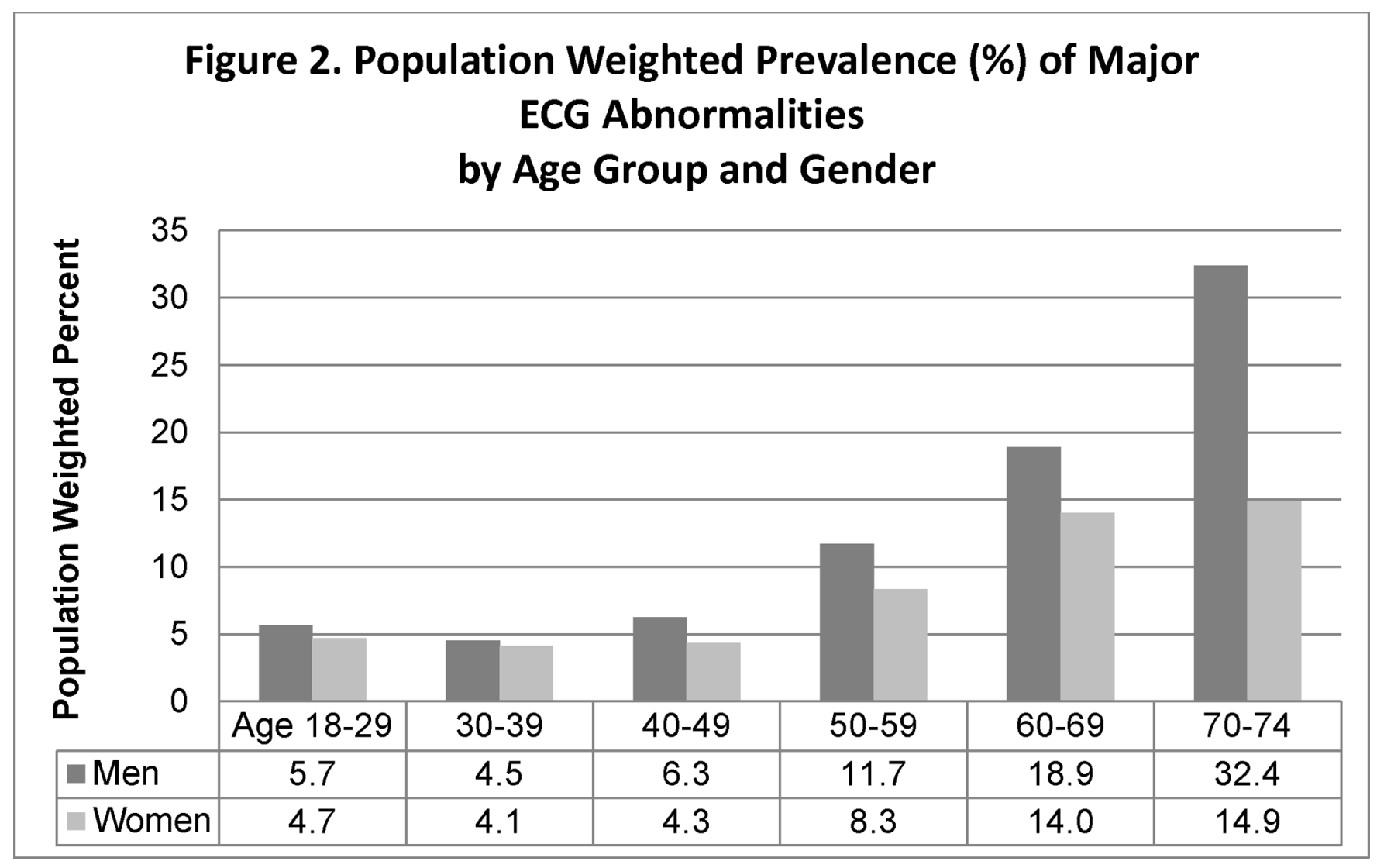

Figure 2.

Population weighted prevalence (\%) of major ECG abnormalities by age group and gender.

Data are presented in percentages for six decades of age for both men and women. 
Table 1

Baseline Characteristics of 15,812 HCHS/SOL Participants ${ }^{a}$

\begin{tabular}{|c|c|c|c|}
\hline Characteristic & $\operatorname{Men}(\mathbf{N}=6, \mathbf{3 3 3})$ & Women $(\mathrm{N}=9,479)$ & p-value $b$ \\
\hline \multicolumn{4}{|l|}{ Age (years) } \\
\hline $18-34$ & $40.4 \%$ & $36.7 \%$ & 0.0006 \\
\hline $35-54$ & $40.3 \%$ & $40.5 \%$ & 0.8471 \\
\hline $55-64$ & $11.8 \%$ & $13.4 \%$ & 0.0023 \\
\hline $65+$ & $7.5 \%$ & $9.3 \%$ & 0.0036 \\
\hline Age (years), mean (SD) & $40.23(0.31)$ & $41.80(0.28)$ & $<.0001$ \\
\hline Hypertension or antihypertensive medication, & $21.9 \%$ & $21.5 \%$ & 0.6698 \\
\hline Hypercholesterolemia or lipid lowering medications, & $50.1 \%$ & $35.0 \%$ & $<.0001$ \\
\hline Diabetes mellitus or diabetes medication, & $13.7 \%$ & $15.5 \%$ & 0.0196 \\
\hline \multicolumn{4}{|l|}{ Smoking status } \\
\hline Current & $26.8 \%$ & $16.4 \%$ & $<.0001$ \\
\hline Former & $21.8 \%$ & $12.8 \%$ & $<.0001$ \\
\hline Never & $51.4 \%$ & $70.8 \%$ & $<.0001$ \\
\hline Family history heart attack < Age 55 & $6.8 \%$ & $8.3 \%$ & 0.0109 \\
\hline \multicolumn{4}{|l|}{ Body mass index $\left(\mathrm{kg} / \mathrm{m}^{2}\right)$} \\
\hline$<25$ & $22.7 \%$ & $23.6 \%$ & 0.4271 \\
\hline $25-<30$ & $40.8 \%$ & $33.9 \%$ & $<.0001$ \\
\hline$\geq 30$ & $36.5 \%$ & $42.5 \%$ & $<.0001$ \\
\hline Systolic blood pressure (mmHg), mean (SD) & $123.40(0.28)$ & $116.70(0.32)$ & $<.0001$ \\
\hline Diastolic blood pressure (mmHg), mean (SD) & $73.53(0.23)$ & $70.96(0.21)$ & $<.0001$ \\
\hline Heart rate $(\mathrm{bpm})$, mean $(\mathrm{SD})$ & $61.85(0.26)$ & $63.77(0.17)$ & $<.0001$ \\
\hline Total cholesterol (mg/dl), mean (SD) & $194.48(0.81)$ & $194.27(0.68)$ & 0.8339 \\
\hline \multicolumn{4}{|l|}{ Prior cardiovascular disease } \\
\hline Prior myocardial infarction & $2.6 \%$ & $1.4 \%$ & 0.0001 \\
\hline Revascularization, (CABG, PCI, Stent) & $1.7 \%$ & $1.0 \%$ & 0.0003 \\
\hline Prior Stroke / TIA & $2.3 \%$ & $2.2 \%$ & 0.7178 \\
\hline Rheumatic heart disease & $0.3 \%$ & $0.7 \%$ & 0.0323 \\
\hline Heart failure & $1.6 \%$ & $2.0 \%$ & 0.1607 \\
\hline Mexican & $36.9 \%$ & $38.5 \%$ & 0.1318 \\
\hline Cuban & $22.1 \%$ & $18.5 \%$ & $<.0001$ \\
\hline Puerto Rican & $16.5 \%$ & $14.7 \%$ & 0.0249 \\
\hline Dominican & $8.2 \%$ & $11.7 \%$ & $<.0001$ \\
\hline Central American & $7.4 \%$ & $7.5 \%$ & 0.8061 \\
\hline South American & $4.7 \%$ & $5.1 \%$ & 0.2487 \\
\hline Other / Mixed / Unknown & $4.3 \%$ & $4.1 \%$ & 0.6378 \\
\hline
\end{tabular}

Abbreviations: BMI, body mass index; CABG, coronary artery bypass grafting; PCI, percutaneous coronary intervention; TIA, transient ischemic attack.

${ }^{a}$ All values (except number of persons in headings) weighted for study design and non-response with use of SURVEY versions of SAS procedures. Percents represent column percents from the corresponding $2 \times 2$ table with only participants with the indicated condition or trait displayed. 
${ }^{b} \mathrm{P}$-values from chi-square for $2 \times 2$ cross tabulation for discrete variables or $\mathrm{t}$-test for continuous variables. 
Table 2

Prevalent Electrocardiographic Abnormalities in 15,812 HCHS/SOL Participants (Age Standardized) ${ }^{a}$

\begin{tabular}{|c|c|c|c|}
\hline Abnormality & Men $(n=6,333)$ & Women $(n=9,479)$ & p-value $b$ \\
\hline Major Minnesota Code Abnormalities & \multicolumn{2}{|c|}{ Percent $(95 \%$ CI $)$} & \\
\hline Major Q wave abnormalities (MC 1.1, 1.2) & $2.76(2.21-3.31)$ & $1.36(0.94-1.78)$ & $<.0001$ \\
\hline Minor Q wave plus major ST-T abnormalities (MC $1.3+(4.1$ or 4.2 or 5.1 or 5.2$)$ ) & $0.29(0.17-0.42)$ & $0.37(0.19-0.55)$ & 0.4862 \\
\hline Major isolated ST-T abnormalities (MC 4.1 or 4.2 or 5.1 or 5.2 ) & $3.04(2.53-3.56)$ & $3.62(3.10-4.14)$ & 0.1171 \\
\hline $\begin{array}{l}\text { Left ventricular hypertrophy w/ major ST-T abn (MC } 3.1 \text { or } 3.4)+(4.1 \text { or } 4.2 \text { or } 5.1 \text { or } \\
5.2)\end{array}$ & $0.53(0.31-0.76)$ & $0.21(0.12-0.31)$ & 0.0138 \\
\hline Atrial fibrillation/flutter (MC 8.3) & $0.30(0.11-0.49)$ & $0.04\left(0.00-0.08^{c}\right)$ & 0.0095 \\
\hline Ventricular conduction defects (MC 7.1, 7.2, 7.4, 7.8) & $3.39(2.88-3.90)$ & $1.36(1.01-1.71)$ & $<.0001$ \\
\hline Complete/intermittent LBBB (MC 7.1) & $0.21(0.10-0.32)$ & $0.26(0.12-0.39)$ & 0.5955 \\
\hline Complete/intermittent RBBB (MC 7.2) & $1.53(1.20-1.85)$ & $0.71(0.45-0.97)$ & $<.0001$ \\
\hline Nonspecific IVCD (MC 7.4) & $1.43(1.04-1.81)$ & $0.37(0.16-0.57)$ & $<.0001$ \\
\hline Complete/intermittent RBBB with left anterior hemiblock (MC 7.8) & $0.23(0.06-0.39)$ & $0.03\left(-0.00-0.05^{c}\right)$ & 0.0214 \\
\hline Major AV conduction abnormalities (MC 6.1, 6.2) & $0.00\left(-0.00-0.01^{c}\right)$ & $0.00\left(-0.00-0.01^{c}\right)$ & 0.8995 \\
\hline WPW (MC 6.4) & $0.06\left(-0.02-0.13^{c}\right)$ & $0.03\left(-0.00-0.05^{c}\right)$ & 0.4198 \\
\hline Major QT prolongation index (QTI $\geq 116$ or JTI if QRS $\geq 120$ ) & $0.58(0.31-0.84)$ & $0.54(0.36-0.73)$ & 0.8337 \\
\hline Other major arrhythmias (MC 8.2, 8.4.2 or 8.4.1 w/ HR $\geq 140$ ) & 0 & 0 & -- \\
\hline Artificial pacemaker (MC 6.8) & $0.22(0.07-0.37)$ & $0.02\left(-0.01-0.05^{c}\right)$ & 0.0132 \\
\hline Any major ECG abnormality & $9.20(8.34-10.06)$ & $6.55(5.78-7.32)$ & $<.0001$ \\
\hline \multicolumn{4}{|l|}{ Minor Minnesota Code abnormalities } \\
\hline Minor isolated Q waves (MC 1.3) & $7.71(6.85-8.57)$ & $5.75(4.90-6.61)$ & 0.0009 \\
\hline Minor isolated ST, T abnormalities (MC 4.3, 4.4, 5.3, 5.4) & $5.38(4.66-6.11)$ & $6.65(5.80-7.51)$ & 0.0253 \\
\hline Tall $\mathrm{R}$ waves left (MC 3.1, 3.3, 3.4) & $7.15(6.21-8.08)$ & $3.02(2.43-3.62)$ & $<.0001$ \\
\hline Low voltage (MC 9.1) & $0.82(0.54-1.10)$ & $2.49(2.10-2.88)$ & $<.0001$ \\
\hline Tall $\mathrm{R}$ wave right (MC 3.2) & $0.46(0.18-0.74)$ & $0.02\left(-0.01-0.04^{\mathcal{C}}\right)$ & 0.0024 \\
\hline ST elevation (MC 9.2) & $10.18(9.14-11.21)$ & $1.41(1.05-1.78)$ & $<.0001$ \\
\hline ST elevation (MC 9.2): Anterior leads & $3.10(2.49-3.71)$ & $0.72(0.42-1.01)$ & $<.0001$ \\
\hline ST elevation (MC 9.2): Lateral leads & $1.63(1.19-2.07)$ & $0.55(0.32-0.79)$ & $<.0001$ \\
\hline ST elevation (MC 9.2): Inferior leads & $7.85(6.93-8.77)$ & $0.54(0.33-0.75)$ & $<.0001$ \\
\hline Incomplete RBBB (MC 7.3) & $2.63(1.95-3.30)$ & $1.82(1.39-2.25)$ & 0.0411 \\
\hline Left axis deviation (MC 2.1) & $2.30(1.82-2.78)$ & $1.35(0.82-1.88)$ & 0.0109 \\
\hline Right axis deviation (MC 2.2) & $0.08(0.02-0.14)$ & $0.00\left(-0.00-0.01^{c}\right)$ & 0.0113 \\
\hline Minor QT prolongation index (QTI $\geq 112<116$ or JTI if QRS $\geq 120$ ) & $0.66(0.46-0.87)$ & $2.55(1.92-3.18)$ & $<.0001$ \\
\hline Frequent VPB (MC 8.1.2, 8.1.3, 8.1.5) & $0.98(0.64-1.31)$ & $0.53(0.32-0.74)$ & 0.0308 \\
\hline Sinus bradycardia (MC 8.8) & $8.50(7.47-9.53)$ & $4.20(3.65-4.74)$ & $<.0001$ \\
\hline Other minor abnormalities (MC 6.3, 6.5, 8.1.1, 8.1.4, 8.4.1, 8.7, 9.3) & $6.70(5.82-7.58)$ & $6.48(5.76-7.21)$ & 0.7091 \\
\hline
\end{tabular}

Abbreviations: ECG, electrocardiogram; LBBB, left bundle branch block; RBBB, right bundle branch block; IVCD, intraventricular conduction delay; AV, atrio-ventricular; WPW, Wolff-Parkinson-White; VPB, ventricular premature beats.

${ }^{a}$ All values (except number of persons in headings) weighted for study design and non-response with use of SURVEY versions of SAS procedures and Age Standardized to the 2000 US Population. 
${ }^{b}$ Age-adjusted p-value for difference between men and women from SAS SURVEYREG procedure.

${ }^{c}$ Cell contains fewer than five observations. 


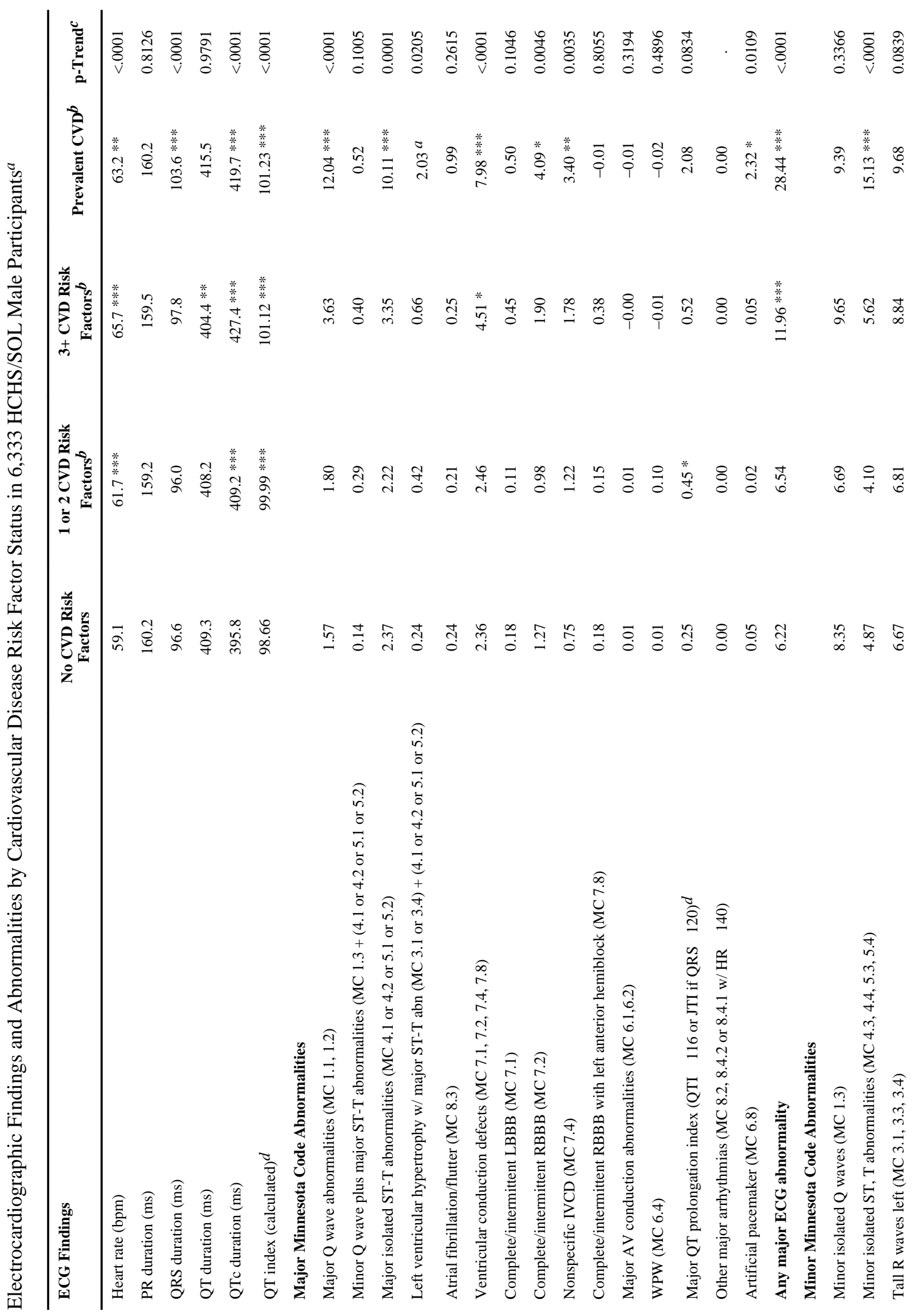


Denes et al.

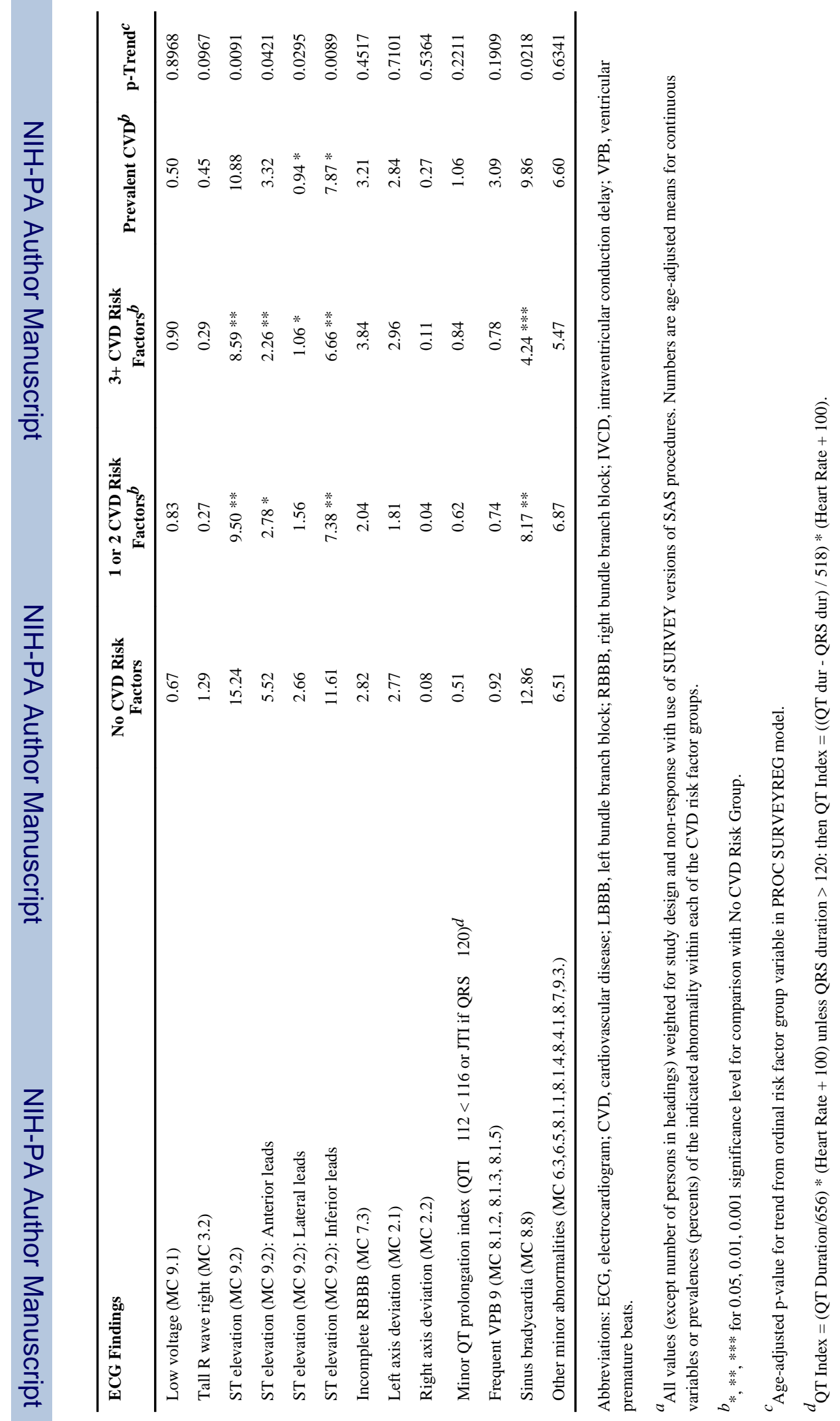




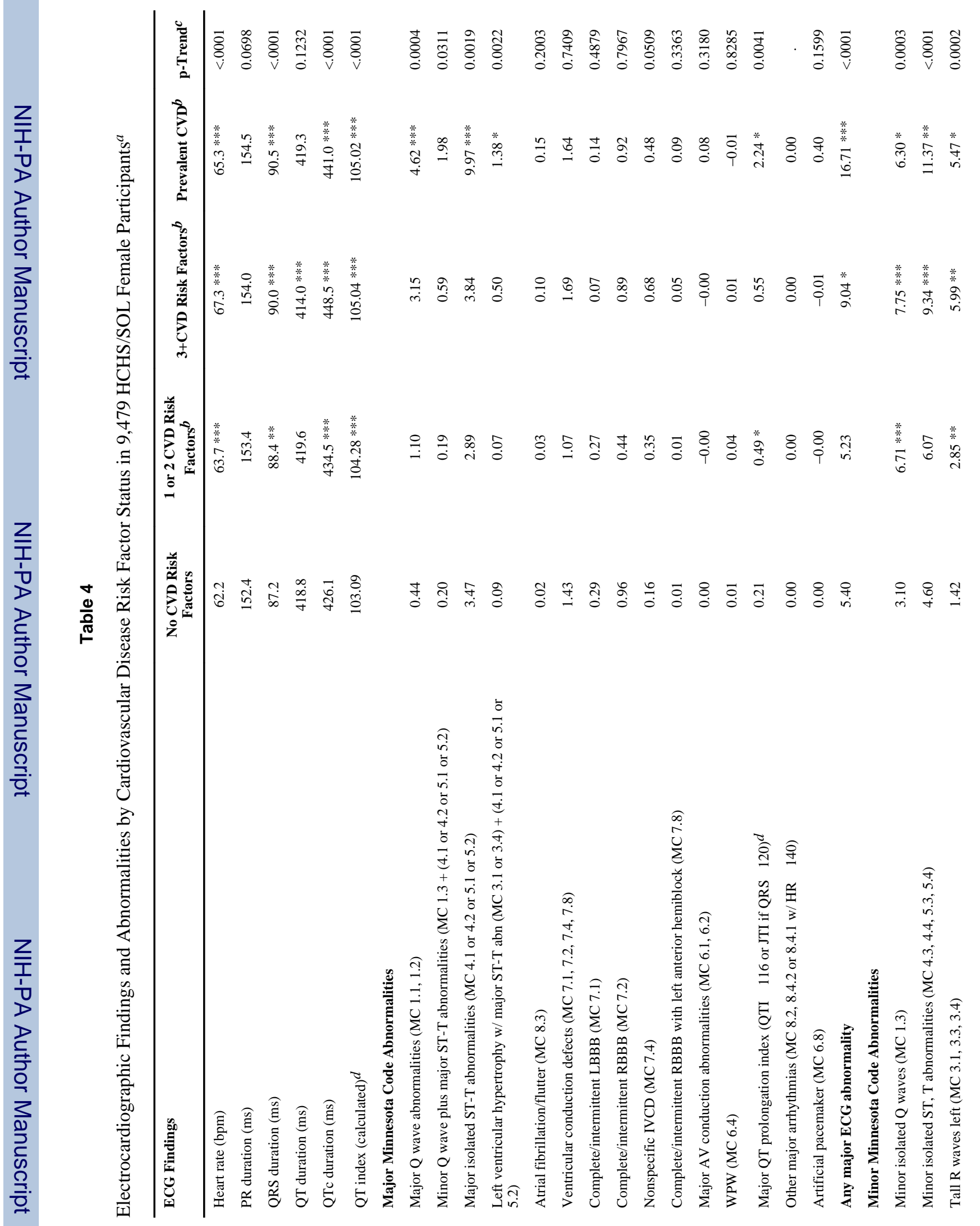




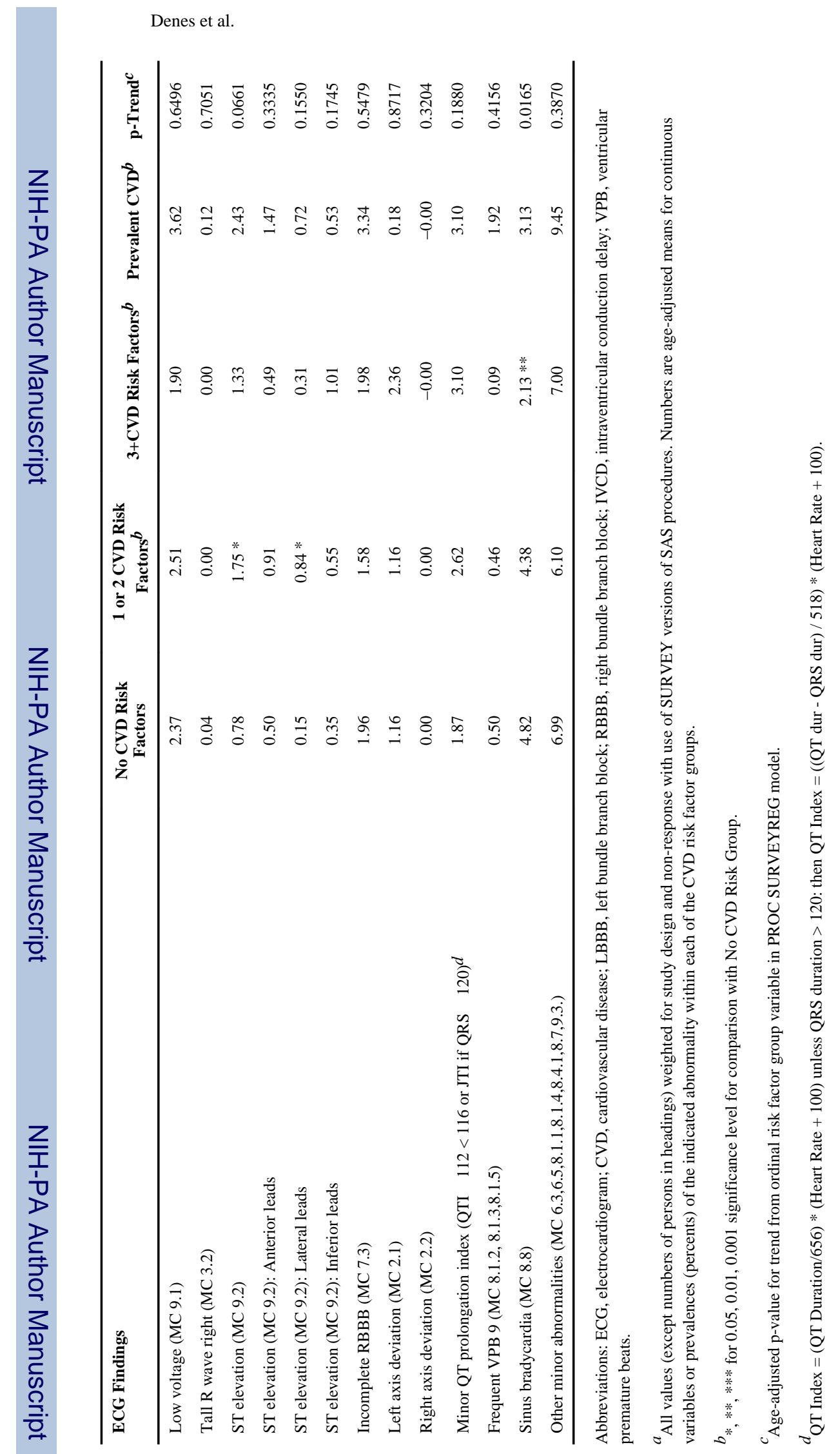

Am J Cardiol. Author manuscript; available in PMC 2014 November 15. 